\title{
Fundamental aspects of thyroid nodule and well-differentiated thyroid cancer for general and family physicians
}

\author{
José Francisco Gallegos-Hernández* \\ Instituto Mexicano del Seguro Social, Centro Médico Nacional Siglo XXI, Oncology Hospital, Mexico City, Mexico
}

\begin{abstract}
The physician that has the first contact with the patient is the general or family doctor, on whose initial assessment patient treatment success often depends. National and international treatment guidelines are designed for specialists in the area, and the primary care physician often finds them difficult to interpret. The purpose of this document is to offer primary care physicians the fundamentals for the diagnostic and reference process of patients with thyroid nodules and possibly with well-differentiated thyroid cancer, from an objective and pragmatic point of view. Not all thyroid nodules require the same approach, and not all nodules are associated with cancer and neither should they be removed. The bases for a proper diagnosis of a thyroid tumor are patient history, physical examination and ultrasound. The results of these three initial assessment methods shall support the decision on the diagnostic-therapeutic process. This article explains the appropriate way to approach the diagnosis of a thyroid tumor, which studies are unnecessary, and which are the principles of thyroid cancer treatment.
\end{abstract}

KEY WORDS: Thyroid cancer. Family doctor. General practitioner. Well-differentiated thyroid cancer. Ultrasound.

\section{Aspectos fundamentales del nódulo tiroideo y el cáncer bien diferenciado de tiroides para los médicos general y familiar}

\section{Resumen}

El galeno de primer contacto con el paciente es el médico general o familiar, de cuya evaluación inicial muchas veces depende el éxito en el tratamiento de los pacientes. Las guías terapéuticas nacionales e internacionales están diseñadas para especialistas en el área y el médico de primer contacto suele encontrarlas difíciles de interpretar. El objetivo del presente documento es ofrecer al médico de primer contacto los fundamentos para el diagnóstico y proceso de referencia de los pacientes con nódulos tiroideos y eventualmente con cáncer bien diferenciado de tiroides, un punto de vista objetivo y pragmático. No todos los nódulos tiroideos requieren la misma aproximación diagnóstica y no todos los nódulos están asociados con cáncer ni deben ser retirados. Las bases para el adecuado diagnóstico de un tumor tiroideo son la historia clínica, la exploración física y el ultrasonido; los resultados de estos tres métodos iniciales de exploración serán los que orienten el proceso diagnóstico-terapéutico. En el presenta artículo se explica la forma adecuada para el diagnóstico de un tumor tiroideo, los estudios innecesarios y los principios del tratamiento del cáncer de tiroides.

PALABRAS CLAVE: Cáncer de tiroides. Médico familiar. Médico general. Cáncer bien diferenciado de tiroides. Ultrasonido. 


\section{Introduction}

Thyroid nodules are a rather common entity; it has been estimated that about $35 \%$ of the population will have a thyroid nodule in the course of life.

Self-detection or ultrasound incidental detection of a thyroid nodule is a common complaint with both family doctors and specialists.

Approximately $10 \%$ of thyroid nodules will have thyroid cancer. The most common cancer is known as well-differentiated thyroid cancer (WDTC), and it encompasses three entities: papillary cancer, follicular cancer and mixed or papillary-follicular cancer, all three with a similar diagnostic approach, and can receive the same treatment according to prognostic factors.

In the presence of a patient with a thyroid nodule, the first questioning that we should ask ourselves is whether it is possible for it to be a WDTC, an entity that requires specialized treatment; if not, the treatment will depend on patient symptoms or on his/her preferences. Hence, the art of diagnosis lies in ruling out a thyroid cancer at the office.

There are clinical features that suggest the possibility for a nodule being neoplastic, but the two fundamental diagnostic clues are ultrasonographic characteristics of the nodule and cytology obtained with ultrasound-guided fine-needle biopsy in order to reduce the false negative rate. ${ }^{2}$ Thus, the pillars of the diagnosis of a thyroid tumor are clinical assessment, ultrasound and ultrasound-guided fine-needle aspiration biopsy.

Knowing the thyroid function status is useful to rule out that the nodule is autonomously functioning (thyroid hormone producer), which forces medical treatment; however, it is of no value for ruling out or to confirm a well-differentiated thyroid cancer. In addition, allows to identify a hypothyroid patient and start hormone replacement; hormone treatment administration in euthyroid patients is not indicated, it does not favor the reduction of the nodule and can cause treatment delay. ${ }^{2}$

\section{Clinical evaluation}

Patient history gives some clues about thyroid function alterations such as signs of hiccups or hyperthyroidism; the presence of these symptoms forces thyroid function assessment with thyroid hormone (T3, T3L, T4L and thyroid-stimulating hormone [TSH) determination; however, patients with thyroid nodules usually have no dysfunction symptoms; more than half the patients with thyroid cancer are estimated to be asymptomatic ${ }^{2}$

Patient interrogation must include questioning about data consistent with digestive and airway compression; although the feeling of cervical compression, dysphagia or foreign object sensation are not pathognomonic, they are often associated with neoplasms.

It is essential to evaluate the voice characteristics. True dysphonia (that which does not disappear) may be associated with laryngeal nerve infiltration, particularly to the recurrent laryngeal nerve, and it hardly occurs when a thyroid nodule is benign. Identification of changes in the tone of voice forces to include laryngeal endoscopy as an examination method prior to treatment, with the purpose to assess for chordal or arytenoid fixation secondary to recurrent laryngeal nerve infiltration. ${ }^{2,3}$

\section{Physical examination}

Physical examination should include palpation of the nodule and neck; a stone-hard and fixed nodule is more commonly associated with cancer. Adenopathies in lateral sides of the neck (jugular chains) associated with a thyroid nodule, especially if located at the same side, should be regarded as a sign of alert and regionally advanced WDTC should be ruled out. This association (thyroid nodule-ipsilateral cervical adenopathy) is common, especially in young patients (younger than 40 years) and usually goes unnoticed or is not given due importance, since there is a tendency to think that the adenopathy is due to a reactive or infectious process; this association is an absolute indication for an ultrasound-guided aspiration biopsy-cytology. ${ }^{4}$

\section{Laboratory tests}

There are no specific laboratory tests for the assessment of a thyroid nodule. Complete thyroid profile is indicated to know the thyroid function, regardless of the presence or not of a tumor; most patients with thyroid nodules are euthyroid. However, a decrease in TSH serum levels forces to rule out hyperfunction of the nodule itself or of the entire gland; thyroid hyperfunction is poorly associated with cancer, and, therefore, an autonomously functioning nodule does not rule out cancer, but almost excludes it. 
Serum thyroglobulin determination is often requested, and sometimes its elevation is regarded as a sign of alert; however, thyroglobulin levels are not correlated with neoplasm diagnosis and, therefore, it is not a study that is recommended in the initial assessment of a patient with a thyroid tumor. ${ }^{2}$ Thyroglobulin is only useful in the follow-up of patients with WDTC undergoing total thyroidectomy and ablation with radioactive iodine.

\section{Radiological evaluation}

The essential imaging study for the assessment of a thyroid nodule is ultrasound; it should routinely include not only the thyroid gland but both lateral sides of the neck; an ultrasound that does not fulfill these characteristics should be considered incomplete. The national guidelines for the treatment of thyroid nodules and thyroid cancer ${ }^{3}$ point out that this study should be carried out by radiologists with training in cervical ultrasonography.

Ultrasound can identify with high diagnostic certainty if a thyroid nodule should be suspected of being neoplastic or not. Ultrasonographic characteristics associated with a probable WDTC are hypogenicity, microcalcifications, intranodular vascular flow, a nodule that is taller rather than wider in the transversal plane, infiltrating margins and presence of nodes in any side of the neck with loss of fatty hilum. ${ }^{2}$ Any of these findings is indicative of the need for an ultrasound-guided fine-needle biopsy. Ultrasonographically cystic or spongiform nodules almost completely rule out the presence of WDTC.

The determination of thyroglobulin in aspirate obtained by puncturing a cervical adenopathy is useful, since it diagnoses WDTC metastasis even if cytology was negative for the presence of neoplastic cells; however, it is not a routine study, not all laboratories have the capacity to perform it and it is not considered essential; the Saxon literature reports it as wash-out. ${ }^{5}$

The size of the nodule is not related to the possibility of thyroid cancer; however, the ultrasound study should record it, since it is one of the most important prognostic factors to decide the extent of surgery should it be a WDTC. Other reports that should be obtained from ultrasound are the number of nodules, their location, size, which and how many of them are suspected of being neoplastic and the presence of lateral cervical adenopathies; of the latter, the size, site, side and conglomerate formation or not should be reported, as well as their association with the jugular-carotid axis. ${ }^{5,6}$

\section{Thyroid scintigraphy}

It is usually routinely included in the assessment of a thyroid nodule; however, its only current indication is when there are data suggesting that there is hyperthyroidism or that the nodule is functioning (autonomous producer of thyroid hormones), i.e., decreased TSH, with or without blood thyroid hormone elevation; when this occurs, scintigraphy allows to identify nodules with increased tracer uptake, but in other scenarios it is not recommended. Even the presence of a nodule with decreased tracer uptake or "cold" nodule has little relationship with thyroid cancer: approximately $10 \%$ of cold nodules are neoplastic and, ultimately, with the ultrasonographic findings it will be decided whether or not to perform puncture-cytology. ${ }^{2,3}$

Thyroid scintigraphy with Tc-99 MIBI or tetrophos$\min$ is useful for its negative predictive value, i.e., a nodule with no tracer uptake (negative) in this test has more than $80 \%$ likelihood of being benign; however, most nodules have tracer uptake and the positive predictive value is lower than $10 \%$; it is a study that should not be routinely performed in the initial workup of a thyroid nodule. ${ }^{7}$

\section{Tomography and magnetic resonance imaging}

Imaging studies with tomography or magnetic resonance are indicated when evaluating the extension of the neoplasm to the mediastinum, upper airway or deep cervical fascia is intended; they are not routine in the evaluation of thyroid cancer or thyroid nodules, since usually they do not modify the therapeutic strategy.

\section{Fine-needle aspiration biopsy}

Any nodule that ultrasonographically shows risk of being a WDTC should undergo fine-needle aspiration biopsy (FNAB); the false negative rate is lower if this puncture is carried out guided by ultrasonography. ${ }^{3}$ Cytology evaluation should be carried out by expert cytopathologists, and the Bethesda classification is recommended for its report.

Although aspiration biopsy is recommended in suspicious nodules, it can be obviated if surgical intervention is decided, since histological evaluation in these cases can be made trans-operatively. 
Open biopsies that affect the neck, either to obtain thyroid tissue or cervical adenopathies, should be avoided, since they can compromise subsequent treatment or favor unnecessary morbidity.

\section{Treatment}

Ultrasonographically or FNAB benign thyroid nodules without neoplastic cells can be monitored; if follow-up is decided, performing an ultrasound every eight months is recommended in order to detect ultrasound changes indicating the need for a new biopsy or surgery. Patients who decide on resection of benign nodules or patients with FNAB with neoplastic cells must undergo surgery, which initially consists of hemithyroidectomy of the side of the nodule, with trans-operative study.

The extent of thyroid surgery depends on the prognostic factors in case WDTC is reported. Stratification by risk groups is well known, and hemithyroidectomy is sufficient treatment in low-risk patients, who do not require subsequent administration of radioactive iodine or TSH suppression. . $^{5,8} 9$

Patients with high risk should undergo total thyroidectomy followed by radioactive iodine administration and post-dose whole body scanning.

\section{Neck treatment}

Surgical treatment of lymph node areas will depend on the stage and presence or not of cervical adenopathies; therefore, it is important to identify them during initial workup.

Lymph node surgery in patients with WDTC can be of two types: central dissection and lateral dissection:

a) Central dissection implies peritracheal, perilaryngeal and recurrent laryngeal nerve-adjacent lymph nodes resection; it is indicated when thyroid cancer invades structures outside the gland (T3 or higher), when the tumor is larger than $4 \mathrm{~cm}$, when at the time of surgery, metastases to these lymph nodes are observed, when there is metastasis to the lateral neck due to a high percentage of metastases in central lymph nodes and when there is metastasis to lateral neck (jugular) lymph nodes. It should be carried out by surgeons with experience in thyroid surgery, since it is associated with recurrent laryngeal nerve injury and hypocalcemia; the rate of these complications rises when the surgeon has only occasionally practiced this intervention. ${ }^{5}$ b) Lateral neck dissection (lymph nodes at the jugular levels) is indicated when there are palpable or ultrasonographic adenopathies, or when the presence of metastases has been corroborated by FNAB. It should be carried out facially (en bloc resection of all nodes) and include the upper and middle lower jugular levels and posterior triangle or level V, as well as lymph nodes behind the sternocleidomastoid muscle posterior border.

\section{Radioactive iodine}

It is indicated in high risk patients. Currently, it is not considered a routine treatment and should be preceded by total thyroidectomy. After the dose, which ranges between 100 and $200 \mathrm{mCi}$, whole-body scan should be carried out in order to rule out distant metastases.

\section{Radiotherapy}

Radiotherapy is a controversial treatment, especially in young people (younger than 45 years); it is indicated when there is evidence of tumor infiltration to the neck soft tissues or when complete resection was not possible.

\section{Conclusions}

The primary care physician should be familiarized with patients who present with a thyroid tumor. It is important to conduct an interrogation aimed at finding symptoms that guide to thyroid cancer; physical examination and thyroid and cervical bilateral ultrasound are fundamental to select patients who are candidates for biopsy or surgery.

Every patient with a thyroid nodule should be ultrasonographically evaluated and it is the findings of this study that will determine if the patient is candidate for biopsy, surgery or surveillance.

Ultrasound is the standard study for thyroid nodule preoperative evaluation and follow-up of patients undergoing thyroid cancer surgery; it should be carried out by expert radiologists and assess the characteristics of the nodule and the presence or not of lymph nodes with metastatic appearance.

The presence of palpable lymph nodes in the neck in addition to a thyroid nodule should alert about the high possibility of regionally advanced thyroid cancer; therefore, the diagnosis should not be delayed with symptom treatments. 
The ultrasonographic presence of a suspicious nodule or lymph nodes with metastatic appearance are an indication for the performance of an ultrasound-guided FNAB.

Thyroid scintigraphy and thyroglobulin determination are studies that should not be routinely performed in patients with thyroid nodules.

TSH suppression with thyroid hormones does is not a treatment that is indicated in patients with thyroid nodules and is not recommended, unless the patient is hypothyroid; however, it is of no use to make the nodule disappear.

\section{References}

1. Secretaría de Salud. Guía de práctica clínica. Diagnóstico y tratamiento del nódulo tiroideo. México: Secretaría de Salud; 2009.
2. NCCN Guidelines Thyroid carcinoma, Version 1.2018. EE. UU.: National Comprehensive Cancer Network; 2018.

3. Granados-García M, Gallegos-Hernández JF, Gurrola-Machuca H, Flores-Hernández, L, Pacheco-Bravo I, Villavicencio-Quejeiro MA, et al. Guía de manejo del nódulo tiroideo y del cáncer diferenciado de tiroides de la Sociedad Mexicana de Oncología. GAMO. 2018;17:5-31

4. Liang L, Zheng XC, Hu MJ, Zhang Q, Wang SY, Huang F. Association of benign thyroid diseases with thyroid cancer risk: a meta-analysis of prospective observational studies. J Encocrinol Invest. 2019;42:673-685.

5. Haugen BR, Alexander EK, Bible KC, Doherty GM, Mandel SJ, Nikiforov YE, et al. 2015 American Thyroid Association Management Guidelines for Adult Patients with Thyroid Nodules and Differentiated Thyroid Cancer: the American Thyroid Association Guidelines Task Force on Thyroid Nodules and Differentiated Thyroid Cancer. Thyroid. 2016:26:1-133.

6. Granados-García M, Estrada-Lobato E, Apodaca-Cruz A. Cáncer diferenciado de la tiroides: aspectos generales. Cancerología. 2009;4:65-71.

7. Gallegos-Hernández JF, Pichardo-Romero P, Esparza-Pérez H, Reséndiz-Colosia FA, Minauro-Muñoz GG, Hernández-Hernández DM. Value of $(99 \mathrm{~m})$ Tc tetrofosmin in well-differentiated thyroid cancer. Cir Ciruj. 2009;77:257-259.

8. Gartland RM, Lubitz CC. Impact of extent of surgery on tumor recurrence and survival por papillary thyroid cancer patients. Ann Surg Oncol. 2018;25:2520-2525.

9. Gallegos-Hernández JF. Tratamiento quirúrgico local del cáncer bien diferenciado de tiroides. Controversia resuelta. Acta Med. 2016;14:129-130. 